\title{
Travessias: a institucionalização do ensino médio integrado
}

Crossing: the institutionalization of integrated high school

Wigna Eriony Aparecida de Morais Lustosa*

\section{Silva, Monica Ribeiro da (Org.)}

Ensino médio integrado: travessias

Campinas, SP: Mercado de Letras, 2013.270p.

O livro Ensino médio integrado: travessias, organizado por Monica Ribeiro da Silva, é uma compilação de oito textos que discutem a institucionalização e implementação do ensino médio integrado à Educação Profissional em três estados brasileiros: Paraná, Santa Catarina e Rio Grande do Norte.

Monica Ribeiro da Silva é doutora em Educação pela PUC-SP e professora na Universidade Federal do Paraná (UFPR). Tem vasta produção sobre a Educação Profissional e 14 livros publicados como autora ou organizadora, em sua maioria, com temas sobre o ensino médio integrado, a Educação Profissional integrada à Educação de Jovens e Adultos (Proeja) e Currículo.

O livro resenhado inicia com uma excelente apresentação que informa o leitor sobre as temáticas abordadas nos seus oito capítulos. Toda a discussão gira em torno do Decreto n ${ }^{\circ} 5.154 / 04,{ }^{1}$ e o objetivo geral do livro é compreender o processo de institucionalização e implementação do ensino médio integrado.

No primeiro capítulo, Leda Sheibe e Filomena L. G. Rodrigues da Silva apresentam um estudo de caso de uma escola do município de Maravilha, Santa Catarina, analisando o processo de implantação do ensino médio integrado à Educação Profissional, suas potencialidades e desafios. Essa política de implantação está comprometida com a formação da classe trabalhadora, mediando, pelo processo educativo, as relações de trabalho e educação. Sobre os desafios, destacamos a formação de profissionais envolvidos no projeto e financiamento específico para adequada implantação. Por fim, as autoras

\footnotetext{
* Mestre em Educação. Instituto Federal de Educação, Ciências e Tecnologia do Rio Grande do Norte. Natal, RN, Brasil. wigna.lustosa@ifrn.edu.br
} 
acreditam nessa política, visando a construção de um projeto societário justo que, apesar dos desafios, tem grandes potencialidades comprovadas.

No segundo capítulo, Acácia Z. Kuenzer e Sandra Regina de O. Garcia apresentam suas análises sobre o processo de implantação do ensino médio integrado no Paraná entre 2003 e 2006. Para isso, realizaram entrevistas em cinco escolas, contemplando alunos, professores, gestores e coordenadores. Após as entrevistas, puderam concluir que o processo de implantação constitui um resultado de uma política pública da Seed/DEP e não um experimento educacional. Essa implantação não ocorre como consenso, mas, em algumas escolas, onde houve espaço para discussão de todos os envolvidos, pode contemplar os anseios da comunidade escolar, fortalecendo a escola em muitos aspectos que estão relacionados à integração do ensino. A política que propõe a integração do ensino médio à educação profissional apresenta uma escola de qualidade para a classe trabalhadora, com visão omnilateral. Formular políticas que garantam financiamento e que permitam a efetiva participação daqueles que vivem do trabalho na sua construção, definição e gestão, gera frutos que os atendem de maneira significativa, além de não se ter escolas que estejam interessadas em atender ao capital, e sim, que busquem uma formação humana integral.

O terceiro capítulo, de Wilson João Marcionilio Alves e Andréa Barbosa Gouveia, trata de financiamento e da questão material de custo-aluno/ano. $\mathrm{Na}$ pesquisa foram analisadas 37 escolas do Panará para compreensão do panorama do investimento em educação feito no estado. Os autores consideram pertinente discutir as condições materiais e de financiamento para a Educação Profissional, já que o sucesso dessa política está ligado à existência de recursos. Concluem que há um baixo valor gasto por aluno/ano, o que pode indicar que o aumento do ensino profissional tem a ver com falta de incentivo financeiro. Uma maior transparência nas informações financeiras pode possibilitar clareza entre os custos escolares, os investimentos e os efeitos desse conjunto na qualidade do ensino ofertado.

Dante Henrique Moura, no quarto capítulo, nos apresenta os frutos de pesquisa sobre a implementação, a partir de 2005, do ensino médio integrado aos cursos técnicos no Cefet-RN. Sob o olhar dos sujeitos envolvidos no processo de implantação do ensino médio integrado, o autor se propõe a traçar um panorama sobre o assunto, a fim de comparar o que está proposto nos documentos com sua prática. Em sua maioria, os envolvidos na pesquisa apresentam uma opinião coerente, que fortalece a oferta do ensino médio integrado regular e na 
modalidade EJA, além de estarem de acordo com uma formação politécnica dos sujeitos. Vale ressaltar que ainda falta uma melhor compreensão da concepção do ensino médio integrado, sendo um empecilho para seu avanço.

O quinto capítulo, de autoria de Letícia de Luca Wollmann Saldanha e Rita de Cássia da Silva Oliveira, discute a expansão da educação profissional no estado do Paraná a partir de três eixos: o socioeconômico, a formação histórico-econômica e os aspectos quantitativos e qualitativos, levando em consideração os arranjos produtivos locais que estão relacionados aos cursos profissionais ofertados. O mundo do trabalho exige conhecimentos científico-tecnológicos e sócio-históricos, e a educação profissional integrada ao ensino médio acontece para possibilitar essa compreensão da realidade, levando o sujeito a uma educação libertadora do capitalismo que aliena e limita o trabalhador. A ideia de uma escola emancipadora e politécnica é o grande objetivo da expansão da educação profissional no Paraná, e ela já representa grandes avanços nesse processo.

Monica Ribeiro da Silva e Eloise Medice Colontonio, no sexto capítulo, analisam o processo de implantação do ensino médio integrado a partir de 2003, considerando a política educacional e seus movimentos. As autoras consideram que o estado do Paraná teve avanços nas medidas políticas e educacionais que foram adotadas desde a implantação do ensino médio integrado, já que tudo ocorreu de forma prematura e única. Com a análise documental, verificam que as propostas dos cursos contemplam de forma parcial o que dizem os documentos, e os cursos estão fundamentados na relação que o ensino médio integrado propõe: trabalho, cultura, ciência e tecnologia.

O capítulo 7, de Lucas Barbosa Pelissari, discute o problema do abandono do alunado nos cursos de ensino médio integrado de Tecnologia, e com isso o autor trabalha a questão do fetiche por esses cursos, pois muitas vezes os alunos se matriculam e desconhecem o que estudarão. O fenômeno do abandono nos chama atenção, já que argumentos importantes nos fazem (re)pensar que as suas causas estão fixadas na estrutura da sociedade, tendo relação com fatores culturais e organizacionais do ambiente escolar. Além disso, o autor problematiza as questões de que a área tecnológica é garantia de emprego e que o currículo do ensino médio integrado, mesmo estando baseado em uma educação humana integral, apresenta dificuldades em relacionar cultura, ciência, trabalho e tecnologia, precisando deixar de considerar essas categorias como mercadorias.

O último capítulo do livro, de Elaine Cristina Nascimento e Mário Lopes Amorim, é fruto de uma dissertação de mestrado na qual se discutiu um estudo 
de caso em duas escolas estaduais do estado do Paraná, com entrevistas semiestruturadas e perguntas estruturadas a vinte professores e 45 alunos do curso de ensino médio integrado de Informática. A pesquisa analisou a implantação do ensino médio integrado, levando em consideração o olhar dos jovens que fizeram o curso e os desafios enfrentados por eles após a conclusão. Os autores apresentam dados de evasão que nos fazem refletir sobre a maneira como vem sendo feita a oferta de um ensino médio integrado que apresenta visão politécnica. Os alunos relatam que muitos se matricularam no curso por falta de vaga no ensino médio regular. Um resumo do processo de expansão da Educação Profissional no Paraná nos mostra a realidade vivida pelo estado em todos os sentidos: econômicos, sociais e políticos. Os autores concluem que se a escola que propõe uma formação humana integral ainda não está concluída, as Políticas Educacionais voltadas para uma escola politécnica se apresentam como um avanço significativo no intento de proporcionar esse modelo escolar à classe que vive do trabalho.

Essa obra permite conhecer um panorama do processo de implantação do ensino médio integrado à Educação Profissional. Consideramos de extrema importância sua leitura, já que nos possibilita conhecer os caminhos percorridos pelas Políticas da Educação Profissional em três estados, os desafios enfrentados e suas perspectivas, além de nos apresentar discussões sobre a relação trabalho e educação, sobre uma formação humana integral, omnilateral e politécnica, fortalecendo o campo de produção do conhecimento em Educação Profissional.

Por fim, observamos que o campo de pesquisa sobre a Educação Profissional ainda é escasso, visto que no livro só pudemos conhecer um pouco sobre a realidade de implantação em três estados, confirmando a importância de produzirmos conhecimento sobre essa temática. A travessia é longa e há muito o que investigar e produzir nessa área.

\section{NOTA}

${ }^{1}$ Decreto n. 5.154/2004, de 23 jul. 2004. Estabelece as diretrizes e bases da educação nacional, e dá outras providências. Disponível em: http://www.jusbrasil.com.br/diarios/667744/ pg-1-secao-1-diario-oficial-da-uniao-dou-de-26-07-2004; Acesso em: 11 out. 2014.

Resenha recebida em 17 de julho de 2016. Aprovada em $1^{\circ}$ de setembro de 2016. 